\title{
El impacto de la gestión documental en la transparencia de las Administraciones públicas: la transparencia por diseño ${ }^{1}$
}

\author{
Impact of records management on transparency in public \\ administrations: Transparency by design
}

\author{
Agustí Cerrillo i Martínez \\ Universitat Oberta de Catalunya \\ acerrillo@uoc.edu
}

\section{NOTA BIOGRÁFICA}

Doctor en Derecho y licenciado en Ciencias Políticas y de la Administración. Catedrático de Derecho administrativo en la Universitat Oberta de Catalunya. investigador principal del proyecto "Retos jurídicos del uso de datos masivos para el fomento de la innovación y la buena administración a través de la inteligencia artificial" del Programa Estatal de I+D+i Orientada a los Retos de la Sociedad.

\author{
Anahí Casadesús de Mingo \\ Escuela Superior de Archivística y Gestión de Documentos \\ de la Universidad Autónoma de Barcelona \\ Anahi.Casadesus@uab.cat
}

\section{NOTA BIOGRÁFICA}

Coordinadora de titulación de la Escuela Superior de Archivística y Gestión de Documentos de la Universidad Autónoma de Barcelona (ESAGED-UAB). Máster en Archivística y Gestión de Documentos por la ESAGED-UAB, cursando el programa de Doctorado en la UAB con el título "Transparencia, Gestión Documental, Archivos y Corrupción". Principales líneas de investigación en gestión de riesgos documentales y rendición de cuentas.

\section{RESUMEN}

La gestión documental tiene un impacto significativo en la mejora de la transparencia de la Administración pública. La transparencia por diseño se refiere a la incorporación de las obligaciones de transparencia previstas por la legislación vigente en el ciclo de vida de los documentos para garantizar el acceso efectivo de la ciudadanía a la información pública desde el diseño de los sistemas de gestión documental. En este artículo se examinan los cambios que las Administraciones públicas deben impulsar en sus sistemas de gestión documental para que contribuyan significativamente a la mejora de la transparencia pública y se facilite el acceso a la información. En particular, como estudio de caso, se analizan las previsiones que ha realizado la Ley 19/2014, de 29 de diciembre, de transparencia, acceso a la información pública y buen gobierno de Cataluña.

\section{PALABRAS CLAVE}

Gestión documental; transparencia; información pública; Administraciones públicas.

\footnotetext{
1 Este artículo se ha realizado en el marco del proyecto "Transparencia, Integridad e Innovación Democrática". Programa Estatal de I+D+i Orientada a los Retos de la Sociedad (DER2014-57391- C2-2-R) (2015-2017).
} 


\begin{abstract}
Records management has a great impact on the improvement of transparency in public administration. Transparency by design refers to the inclusion of transparency duties stated by legislation, in the records' life cycle in a way that it guarantees citizens effective access to public information. In this paper, one analyse changes that public administrations have to implement in their records management systems to improve public transparency and to guarantee an easy access to information. In particular, as a case study, provisions made by Law 19/2014, of December 29, on Transparency, Access to Public Information and Good Governance of Catalonia are explored.
\end{abstract}

\title{
KEYWORDS
}

Records Management; Transparency; Public Information; Public Administration.

\section{SUMARIO}

1. INFORMACIÓN Y DOCUMENTOS: LA NECESARIA GESTIÓN DOCUMENTAL PARA LA TRANSPARENCIA PÚBLICA. 2. LAS PREVISIONES DE LA LEY 19/2014 EN MATERIA DE GESTIÓN DOCUMENTAL PARA LA TRANSPARENCIA. 2.1. TRANSPARENCIA ACTIVA Y GESTIÓN DOCUMENTAL. 2.1.1. El sistema integral de información y conocimiento en formato electrónico. 2.1.2. El Portal de la Transparencia. 2.1.3. El cuadro de clasificación documental. 2.2. TRANSPARENCIA PASIVA Y GESTIÓN DOCUMENTAL. 2.2.1. El sistema de gestión de documentos, información y datos integrado que permita la interoperabilidad entre las Administraciones. 2.2.2. Las tablas de valoración documental. 2.3. TRANSPARENCIA COLABORATIVA Y GESTIÓN DOCUMENTAL. 2.4. SÍNTESIS: LOS REQUISITOS PARA LA GESTIÓN DOCUMENTAL EN LA LEGISLACIÓN CATALANA DE TRANSPARENCIA. 3. CONCLUSIONES: LA TRANSPARENCIA POR DISEÑO: UNA OPORTUNIDAD PARA LAS ADMINISTRACIONES PÚBLICAS. REFERENCIAS BIBLIOGRÁFICAS.

\section{INFORMACIÓN Y DOCUMENTOS: LA NECESARIA GESTIÓN DOCUMENTAL PARA LA TRANSPARENCIA PÚBLICA}

La regulación de la transparencia pública ha experimentado una importante evolución en la última década desde el punto de vista de la gestión documental. Su lectura permite observar cómo en 1992, la Ley 30/1992, de 26 de noviembre, de Régimen Jurídico de las Administraciones Públicas y del Procedimiento Administrativo Común regulaba con carácter básico el derecho de acceso a los documentos administrativos que obrasen en un expediente cerrado en la fecha de la solicitud. En cambio, en la actualidad, la Ley 19/2013, de 9 de diciembre, de transparencia, acceso a la información pública y buen gobierno regula, también con carácter básico, la difusión y el derecho de acceso a la información pública. Asimismo, la Ley 37/2007, de 16 de noviembre, sobre reutilización de la información del sector público ha previsto, después de su reforma operada por la Ley 18/2015, de 9 de julio, la difusión de datos públicos en formato abierto. La Ley 39/2015, de 1 de octubre, del Procedimiento Administrativo Común de las Administraciones públicas confirma esta aproximación al reconocer el derecho de acceso a la información pública. De este modo, de acuerdo con la normativa, hoy en día las Administraciones públicas deben difundir y facilitar el acceso y la reutilización a la información, los documentos y los datos públicos dejando a un lado el concepto de documento como único objeto de la transparencia pública.

La evolución del objeto de la transparencia pública tiene importantes consecuencias en la gestión documental, como tendremos oportunidad de observar en las próximas páginas. En efecto, hasta tiempos recientes, los sistemas de gestión documental de las Administraciones públicas se percibían como algo centrado exclusivamente en el control de los documentos a nivel interno, y básicamente, de los documentos en papel. Como afirma Moyano, este control se ha llevado a cabo «con un enfoque casi siempre interno, dirigido al funcionamiento de la organización y a sus trabajadores» (Moyano Collado, 2015, 48).

Sin embargo, en la actualidad, para dar respuesta a las obligaciones de transparencia que establecen las normas, los sistemas de gestión documental deben entenderse más allá de la gestión interna para poder garantizar que la información pública pueda ser puesta a disposición de la ciudadanía garantizando su autenticidad, integridad, trazabilidad y reutilización. De hecho, el cumplimiento de las obligaciones de transparencia pública exige que la transparencia se incorpore en el propio diseño de los sistemas de gestión 
GAPP. Nueva Época - N.1, mayo 2018 - ISSN: 1989-8991 - DOI: 10.24965/gapp.v0i19.10515 - [Págs. 6-16]

El impacto de la gestión documental en la transparencia de las Administraciones públicas: la transparencia por diseño

Agustí Cerrillo i Martínez / Anahí Casadesús de Mingo

documental para, más allá de permitir gestionar la creación o la generación de información y documentos, se facilite también su difusión y permita la reutilización, plasmándose estas dimensiones en las diferentes fases de su ciclo de vida. Estos conceptos, que pueden parecer nuevos, ya estaban contemplados en la primera versión de la norma ISO 15489, publicada en el año 2001 y traducida al castellano en 2006, que se basaba en la Norma Australiana AS 4390, Records Management, del año 1996. En ella se afirmaba que «un sistema de gestión de documentos se convierte en una fuente de información sobre las actividades de la organización que puede servir de apoyo a posteriores actividades y toma de decisiones, al tiempo que garantiza la rendición de cuentas frente a las partes interesadas presentes y futuras» (ISO 15489-1: 2001, 9). Por tanto, la gestión documental no sólo debe entenderse como una herramienta de gestión interna sino también como un instrumento necesario para la transparencia y la rendición de cuentas.

En esta dirección, la transparencia por diseño es un concepto que se refiere al uso de la gestión documental para el cumplimiento de las obligaciones de transparencia. En el ciclo de vida de los documentos ya está incluido el acceso, por lo que no es necesario realizar un cambio en el modo de enfocar el diseño y desarrollo de los sistemas de gestión documental ni tampoco crear nuevos procesos pero es necesario que las Administraciones públicas adquieran conciencia de ello. La incorporación de las obligaciones de transparencia dentro del ciclo de vida documental, garantiza el acceso efectivo de la ciudadanía a la información pública, permitiendo la trazabilidad de los documentos hasta la fuente de origen. Para ello, la transparencia por diseño exige que la transparencia y el acceso a la información pública se tengan en cuenta no a partir de la finalización de un trámite o procedimiento sino desde su inicio, es decir, desde el momento en que la información se genera. La transparencia por diseño requiere saber, en el momento en que se inicia un trámite, si la información y los documentos que generará deberán ser publicados en el portal de transparencia o si van a poder ser objeto del acceso público, cuándo y durante cuánto tiempo. Para que esto pueda ser una realidad es imprescindible integrar la transparencia pública en el sistema de gestión documental de la organización. Esto es así ya que se debe partir necesariamente de un estudio en profundidad de la documentación que se genera en cada uno de los procedimientos que se llevan a cabo, qué circuitos siguen los documentos en el transcurso de la tramitación y qué valores tienen y adquieren a lo largo del ciclo de vida. Partiendo de este análisis puede incorporarse a cualquier documento público a través de metadatos, entendidos como la información estructurada o semi-estructurada que permite la creación, gestión y uso de los documentos a lo largo del tiempo y entre diferentes dominios (UNE-ISO 15489: 2016, 8). De este modo, será susceptible de ser publicada la información sobre su publicidad o difusión, sobre su accesibilidad o reserva, sobre los periodos de conservación, eliminación, publicación, acceso, reutilización... posibilitando la sistematización y automatización de todas estas acciones en línea con el cumplimiento de la legislación vigente. Esto es lo que llamamos transparencia por diseño (de gestión documental).

La legislación vigente no exige con caràcter general que las Administraciones públicas introduzcan cambios en sus sistemes de gestión documental para incrementar la transparència pública. La lectura de la Ley 19/2013, de 9 de diciembre permite observar el desconocimiento del legislador a esta cuestión. La academia tampoco ha prestado atención a ello como se desprende de la lectura de los principales estudios publicados en España sobre la ley estatal de transparencia en los últimos años (Fernández Ramos \& Pérez Monguió, 2014); (Guichot Reina, 2014); (Troncoso Reigada, 2017).

Sin embargo, más allá de la legislación básica sí que existen algunas normas que reconocen, directa o indirectamente, que los sistemas de gestión documental deben ser capaces no sólo de controlar toda la información que está en poder de las Administraciones públicas sino también de contribuir adecuadamente a la difusión de dicha información a través de los portales de transparencia y de datos abiertos. En esta dirección, la Ley 10/2001, de 13 de julio, de Archivos y Documentos dispone que «todas las Administraciones y entidades titulares de documentos públicos deben disponer de un único sistema de gestión documental que garantice el correcto tratamiento de los documentos en las fases activa, semiactiva e inactiva y que permita cumplir con las obligaciones de transparencia» (art.7.1).

De este modo se puede dar respuesta a lo que señala Moyano al observar que «[l]a transparencia requiere sistemas de gestión documental que hagan posible el control de documentos y, por extensión, de contenidos y otros recursos de información desde el mismo momento de su creación y durante todo su ciclo de vida» (Moyano Collado, 2015, 48).

En las próximas páginas nos proponemos conocer las previsiones que en materia de gestión documental han hecho la legislación de transparencia y, en particular, analizar si incorpora la gestión documental como un instrumento necesario para garantizar el cumplimiento de las obligaciones de transparencia previstas y, en última instancia, como una condición para facilitar el acceso efectivo a la información pública 
por parte de la ciudadanía. En concreto, consideramos que la legislación de transparencia no incorpora la transparencia por diseño. Para poder contrastar esta idea, centraremos nuestro análisis en la regulación de los diferentes mecanismos de transparencia realizada por la Ley catalana 19/2014, de 29 de diciembre, de transparencia, acceso a la información pública y buen gobierno (en adelante, Ley 19/2014) pues constituye la única norma de transparencia aprobada hasta el momento en España que incorpora conceptos propios de la gestión documental.

\section{LAS PREVISIONES DE LA LEY 19/2014 EN MATERIA DE GESTIÓN DOCUMENTAL PARA LA TRANSPARENCIA}

La Ley 19/2014 ha regulado y desarrollado los diferentes mecanismos de transparencia pública: la transparencia activa o difusión de información pública, la transparencia pasiva o acceso a la información pública y la transparencia colaborativa o reutilización de la información pública (Cerrillo i Martínez y Ponce Solé, 2015).

Más allá de la detallada regulación de estos mecanismos, la lectura de esta ley permite observar la preocupación del legislador catalán por la gestión documental en relación a la transparencia, pese a que, como tendremos oportunidad de observar en las próximas páginas, gran parte de las referencias incluidas en dicha ley no profundizan lo suficiente ni utilizan una terminología adecuada. La inclusión de estas cuestiones en la Ley 19/2014 se ha visto facilitada por «la renovación radical de la archivística catalana y la configuración de una Administración Pública transparente y democrática al servicio de los ciudadanos» (preámbulo Ley 10/2001, de 13 de julio, de Archivos y Documentos). De hecho, la legislación catalana de archivos y documentos ya había reconocido explícitamente que «la gestión correcta de los documentos es esencial por cuanto se refiere a la seguridad jurídica y a la actuación eficaz y transparente y con apertura a la participación ciudadana». Sin embargo, las previsiones de la Ley 19/2014 sobre la gestión documental en materia de transparencia están formuladas de manera poco precisa y sin un desarrollo suficiente para que sean realmente útiles a las Administraciones públicas catalanas. Es posible que una ley no sea el espacio más adecuado para la definición de aspectos técnicos con precisión pero sí se debería haber hecho un esfuerzo por incluir unos mínimos requisitos de gestión documental que permitieran cumplir de manera más eficaz con las obligaciones de transparencia.

\subsection{Transparencia activa y gestión documental}

La Ley 19/2014 dispone que las Administraciones públicas deben dar a conocer de manera proactiva información relativa a sus ámbitos de actuación con carácter permanente y actualizado de manera que les permitan un amplio y fácil acceso a los datos (art.2.a). Para ello, las Administraciones públicas deben hacer pública en los portales de transparencia, las sedes electrónicas y los sitios web, la información pública sujeta al régimen de transparencia de forma clara, estructurada y en formato reutilizable (art.5.1). La Ley 19/2014 también prevé la obligación de hacer pública una ingente cantidad de información. Sin embargo, son muchas las obligaciones y pocos los recursos. De hecho, uno de los principales retos a los que se enfrentan las Administraciones públicas para dar cumplimiento a lo previsto en dicha norma es gestionar adecuadamente la propia información que se debe difundir: identificar la información sujeta al régimen de transparencia (art.8.1); garantizar la calidad de la información (art.5); facilitar la consulta en formatos fácilmente comprensibles, reutilizables e interoperables (art.6.1.e) y garantizar la actualización de la información indicando la fecha de la última actualización y, en su caso, retirar los contenidos obsoletos (art.5.1.b). Esto sólo puede conseguirse mediante la interrelación de la ley con los estándares, las arquitecturas de metadatos bien definidas y las aplicaciones tecnológicas (Thurston, 2015).

Para facilitar el cumplimiento de las diferentes obligaciones y, en última instancia, lograr una transparencia pública efectiva es necesario garantizar que toda la información que deben difundir las Administraciones públicas esté debidamente clasificada y organizada. Las actividades propias de una organización deberían fijarse en documentos con metadatos asociados que reflejen su contexto específico. Las Administraciones tienen la obligación de implantar un único sistema de gestión documental que garantice el tratamiento correcto de los documentos y la información en las fases activa, semiactiva e inactiva (es decir, durante todo el ciclo de vida) con el fin de cumplir con sus obligaciones de transparencia. La gestión documental debe entenderse como la base técnica para el desarrollo del llamado por la ley «sistema integral de información», 
que será analizado a continuación. En esta dirección, la Ley 10/2001, de 13 de julio, de Archivos y Documentos prevé que los archivos del Sistema de Archivos de Cataluña deben hacer públicos los instrumentos de descripción documental que permiten a investigadores y ciudadanos localizar la documentación de que disponen; hacer público el registro de eliminación de documentos; hacer públicas las limitaciones a la consulta de documentos custodiados e informar de la fecha en que dichos documentos son accesibles; e informar a los usuarios de su derecho a reclamar y de los procedimientos a seguir en el supuesto de denegarse su derecho de acceso (art.35.1).

En particular, desde el punto de vista de la transparencia por diseño, el sistema de gestión documental debe permitir garantizar el cumplimiento de las obligaciones de transparencia a todas las fases del ciclo de vida documental.

Por lo que respecta a la creación e incorporación de los documentos en el sistema de gestión documental, debe permitir incluir información sobre la relación entre el documento, su productor y el contexto en el que se originó, sus relaciones con otros documentos y con el propio sistema de gestión. Para ello, el documento debe clasificarse siguiendo una categoría que le asignará automáticamente una serie de metadatos asociados para garantizar su fiabilidad, integridad y trazabilidad e informar sobre el nivel de seguridad y acceso o los plazos de conservación.

Por lo que se refiere al almacenamiento, el sistema de gestión documental debe garantizar la disponibilidad, fiabilidad, autenticidad, conservación y accesibilidad de los documentos tanto a nivel interno como para usuarios externos.

En relación a la posible eliminación de documentos, el sistema de gestión documental debe tener presente el marco normativo que regula los plazos de conservación y la posibilidad de eliminar documentos siempre que se garantice que el documento ya no se necesita o que la información que recoge sea accesible a través de otros medios.

Respecto a la trazabilidad, el sistema de gestión documental debe permitir supervisar el uso de la información en relación con la seguridad y el mantenimiento de los sistemas y facilitar una pista de auditoría de las operaciones relacionadas con los documentos.

Por último, el sistema de gestión de documentos también debe garantizar la interoperabilidad, no sólo entre distintas Administraciones públicas sino que también debe ser interoperable la aplicación (o aplicaciones) de gestión de documentos con el portal de transparencia de la organización. Esto permitirá, a través de la información consignada en unos metadatos específicos, una publicación sistematizada y potencialmente automatizada de la información objeto de publicidad activa así como de aquella otra información que la organización decida publicar en su portal de transparencia. La gran ventaja de esta interoperabilidad radica en la importancia de poder acceder a la fuente original de la información, al documento, sin el riesgo que supone la publicación de documentos reelaborados, datos descontextualizados o información que no pueda ser contrastada.

En esta dirección, la propia norma de transparencia establece algunos elementos relativos a la gestión de los documentos que deben desarrollar las Administraciones públicas para facilitar la transparencia y el conocimiento público de su actividad y funcionamiento.

\subsubsection{El sistema integral de información y conocimiento en formato electrónico}

La Ley 19/2014 prevé que la transparencia de la información pública se debe garantizar a través de un sistema integral de información y conocimiento en formato electrónico (art.5.2). Se considera esa terminología equivocada puesto que para poder garantizar la transparencia lo que necesitan las organizaciones son sistemas de gestión documental. El legislador confunde estos conceptos, dificultando la incorporación de la transparencia por diseño en los organismos públicos y generando confusión a los profesionales que deberán dar cumplimiento a la ley.

Es necesario que las Administraciones públicas puedan gestionar con el mismo sistema no sólo la información necesaria para desarrollar sus actividades propias sino también para facilitar la difusión y el acceso a dicha información. De acuerdo con la Ley 19/2014, dicho sistema no debe ser autónomo o diferente del sistema de gestión de la información interno de la Administración pública, sino que debe ser un único sistema integrado. Nuevamente encontramos otra terminología para referirse a sistema de gestión documental por parte del legislador. En cualquier caso, la referencia a disponer de un único sistema integrado se considera muy positiva ya que permitirá a las organizaciones trabajar de acuerdo a unos criterios específicos y únicos para la gestión de su documentación ya sea tanto con fines exclusivamente internos, como con fines de publicación y acceso. 
En realidad, a lo que la Ley 19/2014 se está refiriendo es a invertir en el diseño de un único sistema de gestión documental, que integre la gestión interna y la gestión para la publicidad de la información y los documentos (que debe ser la misma). Este diseño deberá incluir todo el ciclo de vida documental, desde la creación o incorporación de un documento (y sus metadatos asociados), pasando por la clasificación, la descripción, el almacenamiento, la conservación, el acceso, la disposición, el uso y reutilización, la trazabilidad.

Al respecto, la Ley 19/2014 dice claramente que el diseño de este sistema se debe basar en el uso preferente de los sistemas de gestión de documentos públicos (art.5.2). En este punto, la Ley 19/2014 sigue las recomendaciones y la experiencia internacional. Al respecto se pueden traer a colación las normas ISO cuando reconocen que el sistema de gestión documental es el «sistema de información que incorpora, gestiona y facilita el acceso a los documentos a lo largo del tiempo» (UNE-ISO 30300:2011, 17). Asimismo, es ilustrativo el Third Open Government National Action Plan for the United States of America aprobado en octubre de 2015 cuando señala que «the backbone of a transparent and accountable government is strong records management». Igualmente, Moyano al afirmar que «[e]l control de la totalidad de los documentos mediante la implantación de sistemas de gestión documental es la fase básica y de ello va a depender el buen uso de los documentos, el acceso, el control y la explotación posterior en portales y servicios de transparencia o reutilización» (Moyano Collado, 2015, 47).

Además, la Ley 19/2014 dispone que los sistemas de gestión de documentos deben ser «facilitadores de datos y documentos auténticos» (art.5.2). Este es uno de los principales retos de dichos sistemas así como también de la difusión de la información. Es necesario que las Administraciones públicas puedan garantizar que la información que difunden es auténtica, es decir, que se corresponda con los documentos que constan en sus sistemas de gestión documental. No solamente en relación a las obligaciones de transparencia sino también para garantizar una rendición de cuentas confiable y basada en documentos auténticos. Esto se consigue garantizando acceder a la fuente original de la transparencia, al documento, que por el hecho de haberse incorporado y haberse mantenido dentro de un sistema de gestión documental, podrá demostrarse su autenticidad e integridad.

Por último, respecto a la interoperabilidad debe tenerse en cuenta tanto el Marco de Interoperabilidad del sector público de Cataluña que define la Ley 29/2010, del 3 de agosto, del uso de los medios electrónicos en el sector público de Cataluña (art.19) como los criterios y recomendaciones establecidos en el Esquema Nacional de Interoperabilidad (Real Decreto 4/2010, de 8 de enero) que dispone que las Administraciones públicas deben adoptar una política de gestión de documentos electrónicos que incluirá orientaciones o directrices para la creación y gestión de documentos auténticos, fiables y disponibles a lo largo del tiempo, de acuerdo con las funciones y actividades que le son propias. Asimismo, establece que las Administraciones públicas deben crear repositorios electrónicos, complementarios y equivalentes en cuanto a su función a los archivos convencionales. Estos elementos están desarrollados en la Norma Técnica de Interoperabilidad de política de gestión de documentos electrónicos que establece los protocolos de gestión de los documentos en formato digital y también contempla el deber de conservación de esta documentación (Resolución de 28 de junio de 2012, BOE de 26 de julio).

Sin embargo, la legislación catalana no es suficientemente explícita al definir el papel de la gestión documental en la difusión de la información pública. A pesar de la amplitud con la que la Ley 10/2001, de 13 de julio, de Archivos y Documentos (reformada en este punto por la Ley 20/2015, de 13 de julio) define la gestión documental, no ha previsto explícitamente que la difusión de la información (o el acceso y la reutilización) constituyan finalidades del sistema de gestión documental ni tampoco indicado cómo se deben concretar las obligaciones de transparencia en la gestión documental. De este modo, pese a la reforma en 2015 de la Ley 10/2001, el legislador mantiene una visión interna de la gestión documental y no incluye la difusión de la información ni proyecta abiertamente la transparencia en la gestión documental. Sin embargo, sí que se contempla que las Administraciones públicas «deben disponer de un único sistema de gestión documental que garantice el tratamiento correcto de los documentos en las fases activa, semiactiva e inactiva y que permita cumplir con las obligaciones de transparencia» (art.3 20/2015). La Ley 19/2014 tampoco ha concretado estos aspectos suficientemente.

\subsubsection{El Portal de la Transparencia}

El portal de la transparencia es el instrumento del que se deben dotar las Administraciones públicas catalanas para dar cumplimiento y efectividad a las obligaciones de transparencia (art.5.4). El portal de 
transparencia ofrece recursos y servicios de información destinados a mostrar el funcionamiento, la actividad y la acción de la organización, orientados a la rendición de cuentas y su consulta por parte de los ciudadanos y usuarios. Suele diferenciarse de la web corporativa o sede electrónica, aunque también puede estar integrado en ellas.

La Ley 19/2014 establece que el Portal de la Transparencia es el instrumento básico y general de gestión de documentos públicos (art.5.4). Consideramos que esta afirmación está expresada de manera inversa ya que el instrumento básico es el sistema de gestión de documentos y no el portal. Es el primero el que proporciona las herramientas, convirtiéndose en el instrumento básico para el éxito de cualquier portal de transparencia, en tanto en cuanto captura, gestiona y facilita el acceso a los documentos a lo largo del tiempo (ISO 15489: 2016, 9).

A través del sistema de gestión de documentos y del portal, se da cumplimiento y efectividad a las obligaciones de transparencia. Sin embargo, a pesar de la detallada regulación del portal de la transparencia, la Ley 19/2014 no indica cómo debe integrarse con el sistema de gestión documental.

\subsubsection{El cuadro de clasificación documental}

Según la Ley 19/2014, las Administraciones públicas deben impulsar diferentes acciones para hacer efectivo el principio de transparencia. En particular, se prevé que las Administraciones públicas deben ordenar temáticamente y cronológicamente la información que se difunde a través del Portal de la Transparencia para facilitar su localización fácil e intuitiva (art.6.1.d). Para ello se establece que se debe seguir el cuadro de clasificación documental comparativo [sic] en el caso de que se disponga de él. Se entiende por cuadro de clasificación corporativo (no «comparativo») la herramienta esencial de gestión documental para la recuperación y el control de los documentos y expedientes, en cualquier soporte. Es el instrumento básico para la organización de los documentos que permite tener una visión global y sistemática de la información generada y recibida por la organización. La tendencia mayoritaria apuesta por la elaboración de cuadros de clasificación funcionales y uniformes, es decir, que su estructura no tome como elemento definidor los órganos que generan documentos (dado que cualquier alteración en el organigrama y en la estructura orgánica obligaría a frecuentes cambios) sino que adopta como referente básico las funciones que tiene cada organismo, en la medida en que estas son permanentes y garantizan, en consecuencia, un cuadro de clasificación sólido y de larga duración. Cabe mencionar en este punto la imprecisión del legislador al referirse a la clasificación documental comparativa en vez de a la clasificación documental corporativa.

La construcción del cuadro de clasificación supone integrar en un instrumento sistemático un conjunto de informaciones derivadas del análisis de la historia de la organización, su estructura y sus funciones, la identificación de la producción documental, el marco jurídico, la compilación de clasificaciones anteriores (si las hubiera) y el conocimiento exhaustivo de los procedimientos administrativos que se llevan a cabo. Para ello, no es necesario inventar una metodología sino que podemos remitirnos a la Norma Internacional para la descripción de funciones ISDF, que se basa en el principio de que el análisis de las funciones de las instituciones debe convertirse en la base para muchas de las actividades de la gestión de documentos. El cuadro de clasificación debe ser único para toda la organización.

\subsection{Transparencia pasiva y gestión documental}

La Ley 19/2014 reconoce que las personas tienen el derecho a acceder a la información pública (art.18). Este derecho únicamente puede ser denegado cuando pueda suponer un perjuicio para alguno de los límites expresamente previstos en la ley, que deben aplicarse de acuerdo con su finalidad e interpretarse de forma restrictiva en beneficio de la transparencia (art.20). Las personas pueden solicitar la información por cualquier medio que permita tener constancia de su identidad, de la información a la que desean tener acceso y de la forma o el formato en que prefieren tener acceso a la información (art.26).

Para garantizar el acceso a la información es necesario que las Administraciones públicas adopten las medidas organizativas necesarias. En particular, desde la perspectiva de la gestión documental, la Ley 19/2014 prevé que las Administraciones públicas deben establecer un sistema de gestión de documentos, información y datos integrado. El sistema de gestión documental no sólo permite la sistematización de la 
publicación de la información objeto de la transparencia activa sino que facilita enormemente la garantía del derecho de acceso a la información pública a las personas que así lo soliciten. Esto es así debido a que resultará mucho más sencilla la recuperación de la información pertinente, permitiendo cumplir los plazos que marca la ley sin demoras innecesarias.

Asimismo, también deberán elaborar, tal y como dispone Ley 10/2001, las tablas de valoración documental en las que se regula el régimen general de acceso a los documentos facilitando la garantía del derecho de acceso, a las que se hará referencia posteriormente.

\subsubsection{El sistema de gestión de documentos, información y datos integrado que permita la interoperabilidad entre las Administraciones}

La Ley 19/2014 dispone que las Administraciones públicas con el fin de garantizar el cumplimiento del derecho de acceso a la información pública deben establecer un sistema de gestión de documentos, información y datos integrado que permita la interoperatividad [sic] entre las Administraciones públicas, la localización de cualquier documento o información y la vinculación automática de cada documento o conjunto de documentos a su régimen de acceso y publicidad (art.19.3).

En primer lugar, el sistema debe permitir la gestión integrada de documentos, información y datos. Esto se consigue a través del diseño de un único sistema de gestión documental para la organización.

En segundo lugar, el sistema debe facilitar la localización de cualquier documento o información. Esto se consigue a través de la definición de un esquema de metadatos para la organización que permita vincular la información de contexto y descriptiva a los documentos. Esto permitirá su recuperación y localización a través de la realización de la búsqueda en el sistema de gestión documental.

En tercer lugar, el sistema debe permitir la vinculación automática de cada documento o conjunto de documentos a su régimen de acceso y publicidad. En relación a esta cuestión debemos remitirnos al siguiente apartado.

\subsubsection{Las tablas de valoración documental}

La Ley 10/2001 dispone que la Comisión Nacional de Acceso, Valoración y Selección Documental elabora las tablas de acceso y valoración documental, controla su correcta aplicación y resuelve las solicitudes de valoración de documentos públicos haciendo constar el régimen general aplicable al acceso a los documentos (art.19.2).

Según el Decreto 13/2008, de 22 de enero, sobre acceso, valoración y selección de documentos las tablas de valoración y acceso documental determinan, para cada serie documental, el plazo de conservación y los criterios sobre la aplicación de la normativa que rige el acceso a los documentos (art.10).

La valoración documental es una metodología con una amplia trayectoria en el mundo de la gestión documental sin que, en general, se hayan identificado incidencias. La Comisión Nacional de Acceso, Valoración y Selección Documental ha tenido particularmente en cuenta la accesibilidad de los documentos al adoptar dichas tablas.

Es fundamental mencionar en este apartado la aplicación de la metodología de valoración a los documentos y la información publicados y mantenidos en los portales de transparencia ya que resulta de igual modo inviable e insostenible mantenerlos en el portal ad aeternum. Se deberá decidir el tiempo que cada información deberá estar accesible a través del portal. Esta medida permite el ahorro de costes y un mejor control sobre la transparencia en las Administraciones públicas. Además, está totalmente relacionado con la actualización de la información publicada y permite evitar la permanencia de información obsoleta en el portal de transparencia.

\subsection{Transparencia colaborativa y gestión documental}

La Ley 19/2014 prevé que las Administraciones públicas deben facilitar a las personas el acceso a la información en formatos reutilizables y que esta información podrá ser reutilizada con cualquier objetivo lícito, especialmente, la difusión de la información pública (art.16). Los formatos que permiten la reutilización de la información convierten la transparencia y el acceso a la información en algo más que un acto contemplativo o meramente informativo, permitiendo fomentar la participación ciudadana, el compromiso social y, sobre todo, incentivar la actividad económica (Soler et al., 2016, 23). 
Para facilitar la reutilización de la información y, por ende, la transparencia colaborativa, la Ley 37/2007 prevé que las Administraciones públicas deben crear «sistemas de gestión documental que permitan a los ciudadanos la adecuada recuperación de la información, disponibles en línea y que enlacen con los sistemas de gestión puestos a disposición de los ciudadanos por otras Administraciones».

Es necesario que los formatos reutilizables proporcionen la información pública de manera estructurada (por ejemplo, en formato xls o csv). Estos formatos deben contemplar la compatibilidad con el máximo número posible de sistemas de recuperación de información o de lectura de ficheros. Por otro lado, es importante que sean conocidos, que su uso sea popular, prestando especial atención a los formatos abiertos y libres (Soler et al., 2016, 23).

\subsection{Síntesis: los requisitos para la gestión documental en la legislación catalana de transparencia}

La Ley 19/2014 ha conectado las obligaciones de transparencia con la gestión documental (Matas i Balaguer, 2015, 36). Sin embargo, como hemos tenido oportunidad de observar a lo largo de estas páginas esta conexión se ha realizado básicamente a nivel externo, es decir, para garantizar la disponibilidad de la información para la ciudadanía. No se han previsto explícitamente mecanismos internos para facilitar que la gestión de la información y los documentos que generan las Administraciones públicas en el ejercicio de sus competencias permita garantizar su transparencia. En cambio, la Ley 10/2001 sí ha definido la gestión documental haciendo mención explícita a la necesidad de tener presente las obligaciones de transparencia en su diseño.

La legislación vigente en Cataluña establece diferentes requisitos en materia de gestión documental para garantizar la transparencia de las Administraciones públicas y, por ende, el conocimiento efectivo de la información pública por parte de la ciudadanía. Sin embargo, estos requisitos, aunque se valoran de manera positiva, no son suficientes para garantizar una transparencia real, puesto que se quedan en un nivel superficial y poco concreto. Si bien una ley no es el mejor instrumento para incluir aspectos técnicos, ya que se han incluido en ésta referencias a dichos aspectos, hubiese resultado más provechoso el empleo correcto de la terminología y una mayor profundización sobre qué se espera de los llamados «sistemas integrales de información, datos y documentos», qué profesionales están llamados a implantarlos y cuál es su relación con el cumplimiento efectivo de la ley.

En resumen, a la vista de la legislación catalana se puede destacar que dichos sistemas de gestión de documentos, información y datos deben ser como mínimo integrales, interoperables, electrónicos, y que permitan el acceso fácil y gratuito a la información pública así como la localización y recuperación de cualquier documento o información, indicando para cada documento su régimen de acceso y publicidad.

Esto sólo puede conseguirse a partir del diseño de la transparencia desde la gestión documental, ya que incluye todos estos aspectos en su metodología.

\section{CONCLUSIONES: LA TRANSPARENCIA POR DISEÑO: UNA OPORTUNIDAD PARA LAS ADMINISTRACIONES PÚBLICAS}

A lo largo de este trabajo hemos tenido la oportunidad de observar que la transparencia por diseño se refiere la consecución de los objetivos de transparencia a partir de la aplicación de la metodología de gestión documental. El objeto de la transparencia son los documentos y la información que cada Administración pública genera y gestiona en el ejercicio de sus funciones. Para su propio funcionamiento y control, la Administración pública debe definir políticas de gestión de documentos así como implantar sistemas de gestión documental, que ya incorporen en su diseño los procesos de acceso, publicidad y reutilización. Se trata de simplificar la transparencia, consiguiendo a la vez una mayor capacidad para cumplir con la normativa en esta materia.

Los sistemas de gestión documental permiten automatizar y sistematizar la publicidad activa, gestionar el acceso a la información, garantizar las limitaciones de la transparencia y la protección de datos personales, facilitar las conversiones a formatos abiertos y reutilizables, y permitir la actualización de información, entre otros. Por tanto, no es necesario desarrollar nuevas metodologías, sino aplicar las ya existentes y aunar esfuerzos a nivel interno para conseguir una mejor organización para la transparencia pública.

La Ley 19/2014 se refiere a la gestión documental como instrumento al servicio de la transparencia pública siendo pionera entre las leyes de transparencia aprobadas en los últimos años. Sin embargo, en línea 
con lo anteriormente expuesto, a nuestro entender el simple cumplimiento de lo previsto en la Ley 19/2014 no permite conseguir que por sí mismo se lleve a cabo un cambio de visión en relación a la gestión documental ni que se integre la transparencia por diseño en las Administraciones públicas, debido a la regulación imprecisa de estas cuestiones. Falta, en primer lugar, un uso adecuado de los conceptos clave de gestión documental para evitar algunas de las confusiones que ha generado el propio legislador. En segundo lugar, también serían necesarias referencias a la sostenibilidad y mejora de los sistemas de gestión de documentos ya existentes en lugar de fomentar la creación de nuevos sistemas con la pretensión de abarcarlo todo. Esto implica que la Ley 19/2014, así como en cualquier otra norma que regule aspectos de acceso a la información y transparencia, debería focalizar los esfuerzos a mejorar los sistemas de gestión documental que ya están funcionando en las Administraciones públicas con el objetivo de fomentar la transparencia por diseño en dichos organismos. En tercer lugar, se debería valorar la oportunidad que la propia legislación permita el normal desarrollo de los procesos de gestión documental normalizados a nivel internacional (como, por ejemplo, la valoración y eliminación de documentos) en lugar de su prohibición. Esto permitiría un uso sostenible de los recursos en las Administraciones públicas y una gestión saludable y beneficiosa de su información y documentación.

De hecho, a la vista de la regulación vigente, todo apunta a que el cumplimiento de las obligaciones de transparencia por las Administraciones públicas catalanas no supondrá una mayor inversión en sus sistemas de gestión documental para que, a su vez, puedan tener una mayor contribución a la transparencia pública. Al contrario, como manifiesta Moyano «la práctica ha sido dejar a los sistemas de gestión documental al margen de los portales de transparencia e incluso de los de reutilización, creando una brecha entre los departamentos de archivo y gestión documental, como órganos competentes en la recepción y tratamiento de la documentación, y los nuevos servicios de datos abiertos y reutilización de la información pública» (Moyano Collado, 2015 , 54). Esto dificultará la sistematización y automatización de la publicación de información y documentos obligada por la ley, conllevando una inversión y gasto innecesarios en recursos (personal, tiempo,...) que, incorporando la transparencia por diseño, se podrían ahorrar. Por ello, hubiese sido deseable que la propia normativa hubiese incorporado estos aspectos de manera más detallada, incluyendo instrumentos básicos para la gestión de la información y los documentos, como la clasificación, la descripción y la valoración, entre otros, o hubiese remitido a la legislación vigente en Cataluña materia de archivos y gestión documental. Sólo así se consigue una gestión íntegra de la documentación y se facilita la transparencia pública de cualquier organismo.

\section{REFERENCIAS BIBLIOGRÁFICAS}

AENOR, 2006. UNE-ISO/TR 15891-1. Información y documentación. Gestión documental. Parte 1: Consideraciones generales.

AENOR, 2006. UNE-ISO/TR 15891-2. Información y documentación. Gestión documental. Parte 2: Directrices.

AENOR, 2011. UNE-ISO 30300. Información y documentación. Sistemas de gestión para los documentos. Fundamentos y vocabulario.

AENOR, 2011. UNE-ISO 30301. Información y documentación. Sistemas de gestión para los documentos. Requisitos.

AENOR, 2016. UNE-ISO 15489-1. Información y documentación. Gestión de documentos. Parte 1: Conceptos y principios.

CERRILLO I MARTÍNEZ, A. y PONCE SOLÉ, J. (editores) (2015). Transparència, accés a la informació i bon govern a Catalunya. Comentaris de la Llei 19/2014, de 9 de desembre; Editorial UOC-Escola d'Administració Pública de Catalunya, pág. 362; Barcelona.

FERNÁNDEZ RAMOS, S. \& PÉREZ MONGUIÓ, J. M. (2014). Transparencia, Acceso a la Información y Buen Gobierno. Ley 19/2013, de 9 de diciembre. Cizur Menor: Thomson-Reuters-Aranzadi.

GUICHOT REINA, E. (ed.) (2014). Transparencia, Acceso a la Información y Buen Gobierno. Estudio de la Ley 19/2013, de 9 de diciembre. Madrid: Tecnos. https://doi.org/10.24965/reala.v0i2.10200.

MATAS I BALAGUER, J. (2015). "Notes sobre les Ileis de transparència", Lligall, Revista Catalana d'Arxivistica, 38, 22-44. Accesible en: http://www.arxivers.com/index.php/documents/publicacions/revista-lligall-1/lligall-38-1/1520-21-notes-sobre-les-lleis/file (última consulta: octubre de 2017).

MOYANO COLLADO, J. (2015). "Gestión documental en un marco de transparencia y reutilización de la información". Lligall, Revista Catalana d'Arxivistica, 38. Accesible en: http://www.arxivers.com/index.php/documents/ publicacions/revista-lligall-1/lligall-38-1/1521-2-2-gestion-documental/file (última consulta: octubre de 2017).

ROBERTS, A. (2006). "Dashed Expectations: Governmental adaptation to transparency rules", en HOOD, C.; HEALD, D. (editores), Transparency. The key to better governance? Oxford University Press for The British Academy, pág. 107-126; Oxford. https://doi.org/10.5871/bacad/9780197263839.003.0007. 
RUIZ, V.; SOLER, J. (coord.); CAPELLADES, A.; CASADESÚS, A.; LOPERA, S.; MARIA, A. y MEINHARDT, C. (2016). Model de maduresa en gestió documental per a la transparència i la publicitat activa. Associació ArxiversGestors documentals de Catalunya, pág. 52; Barcelona. Accesible en: http://www.arxivers.com/index.php/ documents/l-associacio-1/1565-maduresa-en-gestio-documental-per-la-transparencia/file (última consulta: octubre de 2017).

STANDARDS AUSTRALIA, Australian Standard AS 4390-1996. Records Management.

THURSTON, A. (2015). Right to Information. Managing Records and Information for Transparent, Accountable, and Inclusive Governance in the Digital Environtment: Lessons from Nordic Countries. The World Bank, pág. 60; Washington. Accesible en: http://www.irmt.org/wp2/wp-content/uploads/2015/07/Right-to-Information-Lessonsfrom-Nordic-Countries.pdf (última consulta: octubre de 2017).

TRONCOSO REIGADA, A. (ed.) (2017). Comentarios a la ley de transparencia acceso a la informacion publica y buen gobierno. Cizur Menor: Civitas. 